\title{
Factor XIII a-positive dermal dendrocytes and shear wave propagation in human skin
}

\author{
T. Hermanns-Lê, I. Uhoda, C. Piérard-Franchimont and G. E. Piérard \\ University Medical Centre Sart Tilman, Liège, Belgium
}

\begin{abstract}
Background The in vivo interdependence between the phenotypic characteristics of dermal cells and the strain imposed on the tissue has not been studied thoroughly in humans. In particular the mechanical force modulation of Factor XIII a expression in dermal dendrocytes (DD) remains unknown.

Materials and methods The present study compares the numerical density of Factor XIII a-positive DD and the in vivo shear wave velocity in the skin. The investigation was performed in 20 men of normal weight and 20 obese men before and after entering a slimming process.

Results Excess cutaneous fat places the skin under increased intrinsic tension. The resonance running time measurement (RRTM) and the DD density were significantly reduced in overweight individuals. After a short-term but intense slimming process, the same individuals showed a trend to normalization of these two parameters without, however, reaching significance. Pooling all data yielded a significant logarithmic correlation between RRTM values and densities in Factor XIII a-positive DD.
\end{abstract}

Conclusion Factor XIII a expression in human DD may be partially regulated by the intrinsic resting tensions in the skin.

Keywords Dermal dendrocyte, mechanical properties, obesity, skin tension.

Eur $\mathcal{F}$ Clin Invest 2002; 32 (11): 847-851

\section{Introduction}

The interdependence between the tensile properties of human skin and the metabolic activity and phenotype of dermal cells is beyond doubt but has been seldom studied in vivo. In vitro models have shown that extrinsic forces applied to collagen lattices enriched with fibroblasts are responsible for modulating the orientation, gene expression and metabolic activity of these cells [1-6]. As a result, the syntheses of extracellular matrix proteins and proteoglycans, matrix metalloproteinases, transcription factors, cell surface molecules, cytokines and cytoskeletal components are distinct under strained and relaxed mechanical conditions. In particular, up-regulation of insulin-like growth factor- $\beta 1$, connective tissue growth factor and induction of proteinase inhibitors are induced in the strained connective tissue [6].

Department of Dermatopathology, University Medical Centre Sart Tilman, Liège, Belgium (T. Hermanns-Lê, I. Uhoda, C. PiérardFranchimont, G. E. Piérard).

Correspondence to: G. E. Piérard, Department of Dermatopathology, CHU Sart Tilman, B-4000 Liège, Belgium. Fax:

+ 32 43662976; e-mail: gerald.pierard@ulg.ac.be

Received 16 January 2002; accepted 10 April 2002
Factor XIII a is a transglutaminase involved in several distinct biological processes. Among them, it may regulate the deposition and processing of collagen to form the extracellular matrix. These aspects are complex and somewhat controversial [7-12]. It is noteworthy that the cytoplasm of some stromal cells, called dermal dendrocytes (DD), is enriched in Factor XIII a [13-19]. These cells are believed to derive from two main, distinct lineages corresponding to a subset of the monocyte-macrophage series and to resident mesenchymal cells [16]. Their tissue densities are modified in fibrotic and sclerotic conditions, without undisputable evidence for a primary disease manifestation or an event associated with local inflammation $[15,19]$. In addition, the numerical density of Factor XIII a-positive DD may be altered in some genetic disorders affecting the connective tissue structure $[15,17,20-26]$. There is ample evidence that many, if not all, of these disorders are associated with alterations in the tensile properties of the dermis. In addition, a link between Factor XIII a-positive DD and intratissular mechanical stress was suggested experimentally in pigs as Factor XIII a expression was completely inhibited in the skin overlying tissue expanders [27]. We have observed, incidentally, the same quenching effect in the human DD covering epithelial cysts encased in the deep reticular dermis (unpublished observations). 
The aim of this study was to compare some aspects of the relationship between the intrinsic tensile properties of human skin and the numerical density in Factor XIII apositive DD.

\section{Methods}

Twenty healthy men (mean age: $44 \pm 7$ years) with a body mass index (BMI) ranging from $19 \cdot 7$ to 21.5 formed the first group of volunteers enrolled in the study. None of them had lost or gained more than $3 \%$ of body weight over the past 5 years. A second group comprised 20 obese men (mean age: $41 \pm 6$ years) whose BMI ranged from 29 to 35 . They were included in the study before and after having recently lost more than $15 \%$ of their body weight following gastroplasty.

Tensile properties of the skin were measured on the mid part of the volar forearm in all subjects. The assessments were performed in autumn and winter when the skin had not been exposed to sunlight for at least 2 months. The measuring method was based on the physical principle of shear wave propagation [28-32]. Resonance running time measurements (RRTM) were recorded in arbitrary units using the Reviscometer ${ }^{\circledR}$ RVM 600 (C + K electronic, Cologne, Germany) as previously described [31,32]. The probe contains two piezo-electric transducers. When applied to the skin with controlled pressure one transducer transmits ultrasonic shockwaves, and the second is the receiver. The shockwaves propagate through the skin differently according to the viscoelasticity of the skin. The time taken by the waves to travel from the transmitter to the receiver is inversely proportional to the mechanical tensions inside the skin [28-30]. To evaluate standardized resting skin tensions, RRTM assessments were performed when the subjects were sitting with their forearms comfortably positioned on armchairs. Measurements were taken at each test site in four directions. One was along the limb axis and three others were oriented at angles of $45^{\circ}, 90^{\circ}$ and $135^{\circ}$ using a ring fixed to the skin to hold the probe exactly at the same site while positioning it at the different angles [31,32]. For each subject, four RRTM were recorded in each of the four directions. The mean of the 16 multidirectional RRTM values was then calculated for each subject.

A 4-mm diameter skin biopsy was obtained from the RRTM test site in each volunteer. Samples were fixed in formalin and embedded in paraffin. Sections were processed for immunohistochemistry using a polyclonal antibody to Factor XIII a (1:350, Biogenex, San Ramon, CA, USA). The number of Factor XIII a-positive DD was counted throughout the sections in the $0 \cdot 5-\mathrm{mm}$ upper dermis. Assessments were made using a computerized image analyser (Analysis, Olympus) and results were expressed as mean numbers per $\mathrm{mm}^{2}$.

As a result of the asymmetrical distribution of the data, the medians and ranges were calculated for each series of data. Statistical comparisons were made using the KruskalWallis test followed by the Dunn's post test. Regression
Table 1 Medians (range) of the number of Factor XIII a-positive dermal dendrocytes (DD) and of the resonance running time measurements (RRTM, arbitrary units) in 20 normal weight men and in 20 obese men, before and after slimming

\begin{tabular}{lll}
\hline Group & $\begin{array}{l}\text { DD } \\
\left(\text { no. } \mathrm{mm}^{-2}\right)\end{array}$ & $\begin{array}{l}\text { RRTM } \\
(\mathrm{AU})\end{array}$ \\
\hline $\begin{array}{l}\text { Normal men } \\
\begin{array}{l}\text { Obese men } \\
\text { before slimming }\end{array}\end{array}$ & $83.5(52-104)$ & $379(\mathrm{AU})(242-490)$ \\
$\quad 66(38-88)$ & $256(168-344)$ \\
after slimming & $74.5(49-90)$ & $277 \cdot 5(206-361)$ \\
\hline
\end{tabular}

analysis models were applied to evaluate the relationships between the DD numbers and RRTM values. The best model, i.e. linear, logarithmic, exponential, or power, was chosen on the basis of the highest coefficient of correlation $r$. A value of $P$ lower than 0.05 was considered statistically significant.

\section{Results}

The RRTM values were significantly lower $(P<0 \cdot 001)$ in obese subjects than in men of normal weight (Table 1). The slimming process was associated with a trend in increased RRTM without, however, reaching significance (Fig. 1). The difference between normal men and obese men after slimming remained significant $(P<0 \cdot 01)$.

In all subjects, the dermis contained Factor XIII apositive DD and Factor XIII a-negative cells (Fig. 2). The numerical density of Factor XIII a-positive DD was significantly lower $(P<0.001)$ in overweight subjects than in men of normal weight (Table 1). The slimming process was associated with a trend to normalization in the DD density

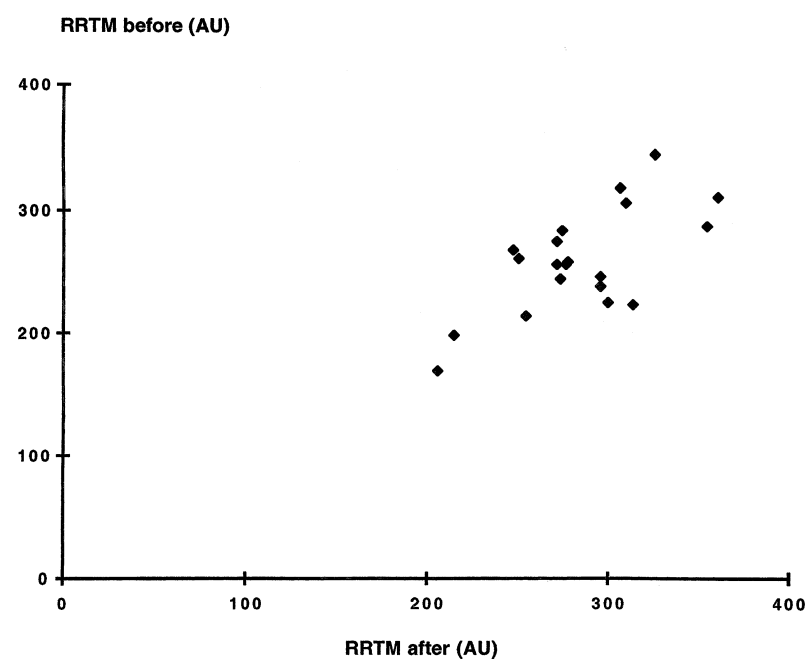

Figure 1 Scatterplot of resonance running time measurement (RRTM) in obese men before and after entering a slimming process. RRTM increases with reduction in weight. 


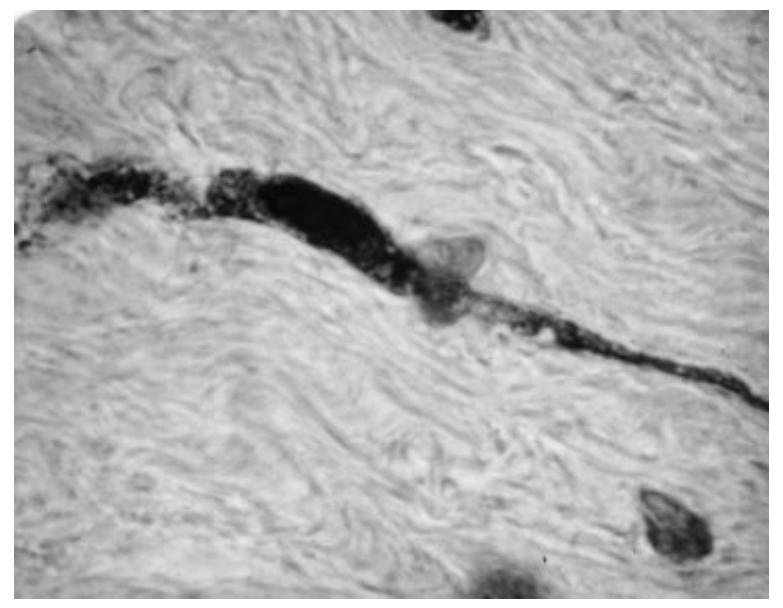

Figure 2 A Factor XIII a-positive dermal dendrocyte and several Factor XIII a-negative cells in the superficial dermis.

DD before $(\mathrm{n} / \mathrm{mm} 2)$

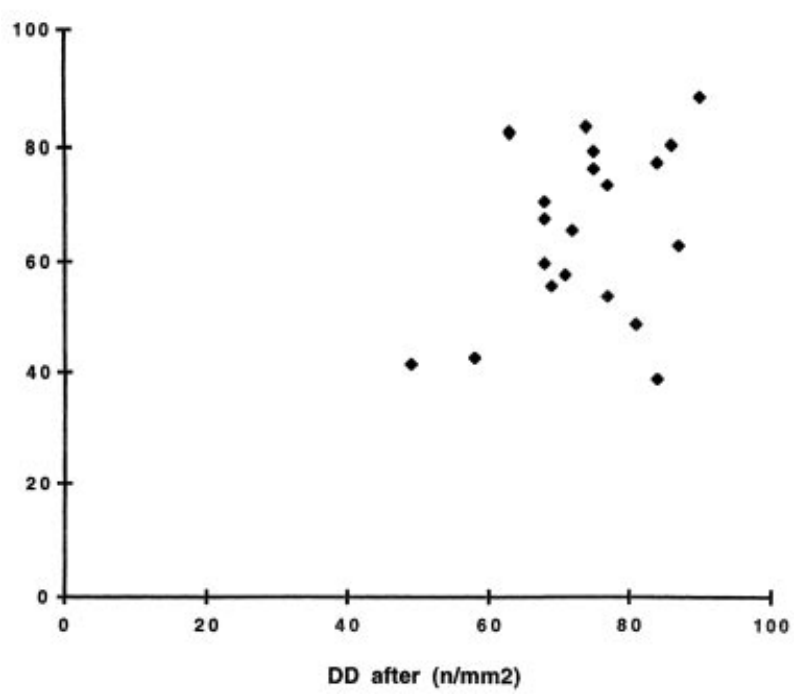

Figure 3 Scatterplot of the numerical density in Factor XIII a-positive dermal dendrocytes (DD) in obese men before and after entering a slimming process. DD increases with reduction in weight.

(Fig. 3). No statistical difference was yielded for this parameter between the slimming subjects and either their former obese status or the men of normal weight.

When pooling all data, a significant logarithmic correlation $(r=0.86, P<0.01)$ was found between Factor XIII a-positive DD numerical densities and the mean RRTM values (Fig. 4).

\section{Discussion}

Healthy skin exhibits both flexibility and relative resistance to deformation, thus permitting body movements. Progres-

\section{DD (n/mm2)}

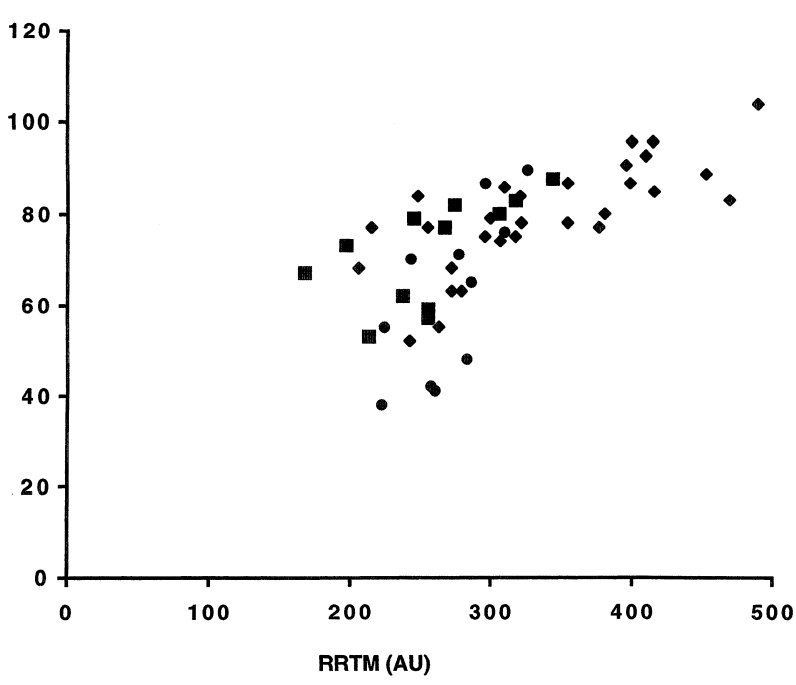

Figure 4 Logarithmic correlation between DD densities and RRTM values. Normal weight men $(\bullet)$, obese men before $(\bullet)$ and after $(\mathbf{\square}$;) weight reduction.

sive resistance to deformation, flexibility and elasticity are normally adequately balanced to fulfil the ideal tensile properties of the skin. Once the deformation ceases, elasticity permits the skin to return spontaneously and progressively to its initial shape [33]. There is ample evidence that the cutaneous mechanical properties of skin vary with body region, age, adiposity and some pathological conditions $[31,33]$. The variation in the firmness and mechanical anisotropy of the skin can be determined by measuring the velocity of shear wave propagation, which changes with body posture, gravitational forces and BMI [31,32]. For this reason, groups of healthy and obese men in the same age range were selected in this study. Their BMI was the single identified variable which could potentially modify the shear wave propagation assessed while respecting a standardized body posture. Indeed the test site was chosen on the inner aspect of the forearm because muscle relaxation can be achieved and easily controlled. In contrast, the abdominal wall, where fat increases most in men, is a mobile structure largely influenced by breathing and muscle contraction. It is also influenced by the volume of the abdominal cavity. In this context, measuring the shear wave propagation in the forearm skin represented a sensitive method allowing the assessment of some tensile properties of skin in a resting condition without the need to impose internal and external strains. Measuring a multidirectional mean RRTM bypasses the problem raised by the anisotropy of the tissue.

The present data on RRTM related to BMI are in line with previous findings [31]. The mean RRTM value was higher in men of normal weight than in overweight individuals. This indicated an increased firmness of the skin with excessive BMI. After gastroplasty and rapid loss of body weight, the skin appeared somewhat slacker with an increased mean RRTM. DD density was lower in obese men 
before gastroplasty and increased when their skin became less tense.

The relationship reported here between the numerical density in Factor XIII a-positive DD and the resting tensions in the skin is a novel finding in human skin. Several physiopathological aspects could be related to it, including skin ageing and some connective tissue disorders. Indeed, cutaneous ageing features a reduction in skin elasticity, combined with slackness and increased unfolding capacity [33]. These functional aspects are associated with a reduction in the number of Factor XIII a-positive DD in the upper mid-dermis [34]. Similar characteristics are found in specific types of Ehlers-Danlos syndrome [24,26]. Hence, in all these examples without exception, cutaneous hyperextensibility is accompanied by a decrease in Factor XIII a-positive DD density. However, these cells may also be slender and rare when the skin becomes overtight. Examples are stiff skin syndrome [20], restrictive dermopathy [21,22], and a number of sclerotic processes [15]. Scleroderma is peculiar for the fact that Factor XIII a-positive DD are more numerous during the active progressive stage $[15,19]$, and may be decreased in the final 'burned out' sclerotic stage [15]. Factor XIII a-positive DD density can also be abated experimentally during tissue expansion [27].

Although a cause-effect relationship is not established between tissue mechanics and the proportion of Factor XIII a-positive DD, the present findings and previous observations can be interpreted in a dynamic model. Assuming DD have adhesion molecules to collagen similar to fibroblasts [6], any mechanical stress transmitted as a strain inside the dermis will stretch these cells. Such an event is likely to be less effective in a loose tissue which requires considerable strain before collagen bundles and their bound cells are set under tension. On the other hand, mechanical stress in the physiological range induces little strain, if any, in an already overtight sclerosis. As collagen bundles are not mobilized, their adherent cells are not stretched. Thus the extreme conditions of loose and stiff skin do not transmit much stress and strain to cells. Such situations show decreased densities in Factor XIII a-positive DD. In contrast, increased tightness in a tissue that remains able to adopt conformational changes transmits the stress and strain to the fibrous networks and their anchored cells. Such a condition is accompanied by an increase in density of Factor XIII a-positive DD. The changes in the Factor XIII a-positive DD described here probably deal with functional phenotypic modulations without modifying the actual number of cells. However, discrete numerical changes in these specific cells cannot be ruled out.

In conclusion, the numerical density of Factor XIII apositive DD in noninflammatory conditions appears to be regulated by the intrinsic cutaneous mechanical tensions. It decreases when the resting skin tensile strength falls outside the normal range. We hypothesize that the adhesion of DD onto the dermal fibrous framework influences their phenotypic characteristics. When the structure is exceedingly loose or conversely stiff, the mechanical stress transmitted to the cells is abated and a quenching effect appears in the intracytoplasmic Factor XIII a accumulation.

\section{References}

1 Delvoye P, Mauch C, Krieg T, Lapière ChM. Contraction of collagen lattices by fibroblasts obtained from patients and animals with heritable disorders of connective tissue. $\mathrm{Br}$ f Dermatol 1986;115:139-46.

2 Lambert C, Soudant P, Nusgens B, Lapière C. Pretranslational regulation of extracellular matrix macromolecules and collagenase expression in fibroblasts by mechanical forces. Lab Invest 1992;66:444-51.

3 Lambert C, Lapière C, Nusgens B. An interleukin-1 loop is induced in human skin fibroblasts upon stress relaxation in a three-dimensional collagen gel but is not involved in the up-regulation of matrix metalloproteinase. $7 \mathrm{Biol}$ Chem 1998;273:23143-9.

4 Eckes B, Kessler D, Aumailley M, Krieg T. Interactions of fibroblasts with the extracellular matrix. Implications for the understanding of fibrosis Springer Semin Immunopathol 1999;21:415-29.

5 Kessler D, Dethlefsen S, Haase I, Plomann M, Hirche F, Krieg $\mathrm{T}$ et al. Fibroblasts in mechanically stressed collagen lattices assume a 'synthetic' phenotype. $\mathcal{F}$ Biol Chem 2001;276:36575-85.

6 Vogel WF. Collagen-receptor signaling in health and disease. Eur f Dermatol 2001;11:506-14.

7 Mosher DF, Schad PE. Cross-linking of fibronectin to collagen by blood coagulation Factor XIII a. $\mathcal{F}$ Clin Invest 1979;64:781-7.

8 Paye M, Nusgens BV, Lapière ChM. Factor XIII of blood coagulation modulates collagen biosynthesis by fibroblasts in vitro. Haemostasis 1989;19:274-83.

9 Barry EL, Mosher DF. Binding and degradation of Factor XIII by cultured fibroblasts. F Biol Chem 1990;265:9302-7.

10 Paye M, Read D, Nusgens B, Lapière ChM. Factor XIII in scleroderma: in vitro studies. Br f Dermatol 1990;122:371-82.

11 Paye M, Nusgens BV, Lapière ChM. Factor XIII of blood coagulation decreases the susceptibility of collagen precursors of proteolysis. Biochim Biophys Acta 1991;1073:437-41.

12 Marzano AV, Federici AB, Gasparini G, Mannucci PM, Caputo R, Berti E. Coagulation factor XIII, endothelial damage and systemic sclerosis. Eur F Dermatol 2000;10:14-17.

13 Arrese Estrada J, Piérard GE. Factor XIII a-positive dendrocytes and the dermal microvascular unit. Dermatologica 1990;180:51-3.

14 Cerio R, Spaull J, Oliver GF, Wilson Jones E. A study of Factor XIII a and Mac 387 immunolabeling in normal and pathological skin. Am f Dermatopathol 1990;12:221-33.

15 Piérard GE, Arrese Estrada E, Piérard-Franchimont C, Deleixhe-Mauhin F. Is there a link between dendrocytes, fibrosis and sclerosis? Dermatologica 1990;181:264-5.

16 Nestle FO, Zheng XG, Thompson CB, Turka LA, Nickoloff BJ. Characterization of dermal dendritic cells obtained from normal human skin reveals phenotype and functionally distinctive subsets. F Immunol 1993;151:6535-45.

17 Piérard-Franchimont C, Fazaa B, Benzarti H, Kort R, Arrese Estrada J, Nikkels AF et al. Phenotypic heterogeneity in the fibroblast-like cells of the dermis. Giorn Int Dermatol Pediatr 1994;6:7-13.

18 Nestle FO, Nickoloff BJ. A fresh morphological and functional look at dermal dendritic cells. F Cutan Pathol 1995;22:385-93.

19 Gilmour TK, Wilkinson B, Breit SN, Kossard S. Analysis of dendritic cell populations using a revised histological staging of morphoea. Br F Dermatol 2000;143:1183-92.

20 Lê T, Piérard GE. Syndrome de la peau cartonnée. Ann Dermatol Venereol 1989;116:807-9. 
21 Piérard-Franchimont C, Piérard GE, Hermanns-Lê T, Arrese Estrada J, Verloes A, Mulliez N. Dermatopathological aspects of restrictive dermopathy. F Pathol 1992;167:223-8.

22 Verloes A, Mulliez N, Gonzales M, Laloux F, Hermanns-Lê T, Piérard GE et al. Restrictive dermopathy. A lethal form of arthrogryphosis multiplex with skin and bone dysplasias. Am f Med Genet 1992;43:539-47.

23 Sueki H, Whitaker D, Buchsbaum M, Murphy GF. Novel interactions between dermal dendrocytes and mast cells in human skin: implications for homeostasis and matrix repair. Lab Invest 1993;69:160-72.

24 Piérard GE, Hermanns-Lê T, Arrese Estrada J, PiérardFranchimont C, Lapière ChM. Structure of the dermis in typeVIIc Ehlers-Danlos syndrome. Am f Dermatopathol 1993;15:127-32.

25 Verloes A, Hermanns-Lê T, Lesenfants S, Lombet J, Lamotte PJ, Crevecoeur-Liégeois $\mathrm{C}$ et al. Koraxitrachitic syndrome: a syndromic form of self-healing collodion baby with residual dappled atrophy of the derma. Am $\mathcal{F}$ Med Genet 1999;86:454-8.

26 Hermanns-Lê T, Piérard GE. Factor XIII a-positive dendrocyte rarefaction in Ehlers-Danlos syndrome, classical type. Am F Dermatopathol 2001;23:427-30.

27 Penneys NS, Rademaker B, Jackson IT, Fasching MC. Loss of Factor XIII a in pig dermis during tissue expansion. F Dermatol Sci 1991;2:62-5.
28 Pereira JM, Mansour JM, Davis BR. Analysis of shear wave propagation in skin: application to an experimental procedure. f Biomech 1990;23:745-51.

29 Mridha M, Odman S, Oberg PA. Mechanical pulse wave propagation in gel, normal and oedematous tissues. $\mathcal{F}$ Biomech 1992;25:1213-18.

30 Vexler A, Polyansky I, Gorodetsky R. Evaluation of skin viscoelasticity and anisotropy by measurement of speed of shear wave propagation with viscoelasticity skin analyser. F Invest Dermatol 1999;113:732-9.

31 Hermanns-Lê T, Jonlet F, Scheen A, Piérard GE. Age-and body mass index-related changes in cutaneous shear wave velocity. Exp Gerontol 2001;36:363-72.

32 Nizet JL, Piérard-Franchimont C, Piérard GE. Influence of the body posture and gravitational forces on shear wave propagation in the skin. Dermatology 2001;202:177-80.

33 Piérard GE, the EEMCO group. EEMCO guidance to the in vivo assessment of tensile functional properties of the skin. Skin Pharmacol Appl Skin Physiol 1999;12:352-62.

34 Piérard-Franchimont C, Arrese Estrada J, Nikkels A, Ben Mosbah T, Deleixhe-Mauhin F, Piérard GE. Dendrocytes et cellules dendritiques épidermiques au cours du photovieillissement. Ann Dermatol Venereol 1990;117:965-7. 